\title{
Angiotensin receptor blockers and risk of cancer: cohort study among people receiving antihypertensive drugs in UK General Practice Research Database
}

\author{
(c) (1) (8)
}

\author{
Krishnan Bhaskaran lecturer in statistical epidemiology ${ }^{1}$, lan Douglas lecturer in \\ pharmacoepidemiology ${ }^{1}$, Stephen Evans professor of pharmacoepidemiology ${ }^{2}$, Tjeerd van Staa \\ head of GPRD research ${ }^{34}$, Liam Smeeth professor of clinical epidemiology ${ }^{1}$
}

${ }^{1}$ Department of Non-Communicable Diseases Epidemiology, London School of Hygiene and Tropical Medicine, London WC1E 7HT, UK; ${ }^{2}$ Medical Statistics Department, London School of Hygiene and Tropical Medicine, London; ${ }^{3}$ General Practice Research Database, Medicines and Healthcare Products Regulatory Agency, London; ${ }^{4}$ Utrecht Institute for Pharmaceutical Sciences, Utrecht University, Utrecht, Netherlands

\begin{abstract}
Objectives To investigate whether there is an association between use of angiotensin receptor blockers and risk of cancer.

Design Cohort study of risk of cancer in people treated with angiotensin receptor blockers compared with angiotensin converting enzyme (ACE) inhibitors. Effects were explored with time updated covariates in Cox models adjusted for age, sex, body mass index (BMI), diabetes and metformin/insulin use, hypertension, heart failure, statin use, socioeconomic status, alcohol, smoking, and calendar year. Absolute changes in risk were predicted from a Poisson model incorporating the strongest determinants of risk from the main analysis.

Setting UK primary care practices contributing to the General Practice Research Database.

Participants 377649 new users of angiotensin receptor blockers or ACE inhibitors with at least one year of initial treatment.

Main outcome measures Adjusted hazard ratios for all cancer and major site specific cancers (breast, lung, colon, prostate) by exposure to angiotensin receptor blockers and by cumulative duration of use.

Results Follow-up ended a median of 4.6 years after the start of treatment; 20203 cancers were observed. There was no evidence of any increase in overall risk of cancer among those ever exposed to angiotensin receptor blockers (adjusted hazard ratio 1.03, 95\% confidence interval 0.99 to $1.06, P=0.10)$. For specific cancers, there was some evidence of an increased risk of breast and prostate cancer (1.11, 1.01 to $1.21, \mathrm{P}=0.02$; and $1.10,1.00$ to $1.20, \mathrm{P}=0.04$; respectively), which in absolute terms corresponded to an estimated 0.5 and 1.1 extra cases, respectively, per 1000 person years of follow-up among those with the highest baseline risk. Longer duration of treatment did not seem to be associated with higher risk ( $P>0.15$ in each case). There was a decreased risk of lung cancer $(0.84,0.75$ to 0.94$)$, but no effect on colon cancer (1.02, 0.91 to 1.16$)$.
\end{abstract}

Conclusions Use of angiotensin receptor blockers was not associated with an increased risk of cancer overall. Observed increased risks for breast and prostate cancer were small in absolute terms, and the lack of association with duration of treatment meant that non-causal explanations could not be excluded.

\section{Introduction}

Angiotensin II type 1 receptor antagonists (hereafter referred to as angiotensin receptor blockers) were first approved in 1995 and are widely used to treat heart failure, hypertension, and diabetic nephropathy. Experimental studies suggest that angiotensin II receptors play a role in regulating angiogenesis, cell proliferation, and tumour progression, providing justification for a theoretical concern about the risk of cancer. ${ }^{1}$ Clinical concerns first arose in 2003 from the CHARM (candesartan in heart failure assessment of reduction in mortality and morbidity) trial, which aimed to assess the role of angiotensin receptor blockers in heart failure. ${ }^{2}$ There were significantly more fatal cancers among people randomised to candesartan than placebo (86 (2.3\%) v 59 (1.6\%), $\mathrm{P}=0.038)$. There was, however, no difference in the incidence of non-fatal cancers, and the investigators suggested the findings for fatal cancer could be attributable to chance. Subsequent trials have produced negative or inconclusive findings but have lacked power. A systematic review and meta-analysis of data from randomised trials found an increased risk of cancer (but not death from cancer) associated with use of angiotensin receptor blockers, ${ }^{3}$ but a more recent meta-analysis incorporating a larger number of trials and using individual patient data found no increase in either overall risk or risk of site specific cancer in users of angiotensin receptor blockers compared with controls. ${ }^{4}$ Data from observational studies have similarly found no increase in risk of cancer 
associated with use of angiotensin receptor blockers, ${ }^{56}$ though such studies had limited follow-up and lacked data on potentially important confounders such as smoking.

We used the large amount of real world follow-up data available in the UK General Practice Research Database (www.gprd.com/ products/database.asp) to assess the overall risk of cancer and the risk of major site specific cancers (lung, breast, prostate, colon) associated with use of angiotensin receptor blockers compared with use of a similar class of drug, angiotensin converting enzyme (ACE) inhibitors, which does not seem to be associated with cancer risk. ${ }^{78}$ Our hypothesis was that those exposed to angiotensin receptor blockers had the same risk of cancer as those exposed only to ACE inhibitors.

\section{Methods}

\section{General Practice Research Database}

The General Practice Research Database is a clinical database containing records from computer systems used by general practitioners to record all clinical information. The database comprises anonymised computerised medical records from general practitioners in the United Kingdom who use the Vision IT system and that have agreed at the practice level to participate; about $8 \%$ of the UK population are currently included. The UK has a publicly funded healthcare system financed through general taxation and free at the point of use to UK residents; general practitioners play a key role as they are responsible for primary healthcare and specialist referrals. Patients are affiliated to a practice, which centralises the medical information from the general practitioners, specialist referrals, and admission to hospital. Demographic information, clinically relevant lifestyle data, prescription details, clinical events, preventive care provided, specialist referrals, and hospital admissions and their major outcomes are all recorded in the database. Data collection started in 1987. Around five million patients are currently registered, with about 12 million patient records. A recent systematic review that collected together studies attempting to validate diagnoses on the database found that among such studies a median of $95 \%$ of neoplasms identified through records in the database could be confirmed with alternate data sources. ${ }^{9}$

\section{Study participants}

We retrieved data on all patients aged $\geq 18$ with a first recorded prescription of an ACE inhibitor or angiotensin receptor blocker in the years 1995-2010 inclusive and dated at least six months after the patient's registration date within General Practice Research Database. Exposure to ACE inhibitors offered an ideal comparison because the two drug classes have similar indications, reducing problems of confounding by indication, and ACE inhibitors themselves do not seem to be associated with risk of cancer. ${ }^{78}$ We chose the six month period to ensure that most of those included would be new users and to exclude prevalent users with unknown previous duration of treatment. ${ }^{10}$ ACE inhibitors were defined as all drugs classified in the British National Formulary, chapter 2.5.5.1, and angiotensin receptor blockers as all drugs classified under chapter 2.5.5.2. ${ }^{11}$ Patients were excluded if they had a recorded diagnosis of cancer on or before their index date (defined as the date of their first prescription of an ACE inhibitor or angiotensin receptor blocker). To prevent pre-existing cancers from affecting our results - for example, through reverse causality—we excluded the initial 12 months of person time after the first prescription for an angiotensin receptor blocker or ACE inhibitor, and individuals who developed cancer or ended follow-up during this period did not contribute to our analyses. We also excluded patients with any treatment breaks of more than 90 days during this initial qualifying period. Individuals switching from an ACE inhibitor to an angiotensin receptor blocker during follow-up left the risk set for 12 months, but could re-enter after 12 months of treatment with an angiotensin receptor blocker; this additional 12 month exclusion period after a switch was intended to prevent the estimation of a spurious association if switching were itself linked to underlying risk of cancer.

\section{Drug exposure and outcomes data}

Exposure status was based on prescriptions data in the database. All prescriptions for an angiotensin receptor blocker or ACE inhibitor were retrieved and the length of each prescription was calculated on the basis of the recorded number of tablets prescribed and the daily dose; when these data were not available we assumed the median value ( 28 days). Clinical events are coded in the database with National Health Service (NHS) Read codes. ${ }^{12}$ The Read codes dictionary was first searched to identify codes indicating malignant neoplasms (excluding non-melanoma skin cancers), by using the Read code hierarchical structure, a search for keywords, and code lists used in earlier studies. We then manually reviewed and confirmed codes identified by the initial search. Subsets of codes specifically indicating neoplasms of the breast, lung, prostate, and colon were also identified during this process. In all cases, we excluded codes for borderline and suspected malignancies. Two researchers (KB and LS) developed and checked the final code lists. Finally, we identified cancers among individuals in the study by matching patients' database records against these final code lists, with no reference to exposure status.

\section{Statistical methods}

Follow-up time began at the end of the 12 month qualifying period after the first prescription of either an ACE inhibitor or angiotensin receptor blocker and ended at the earliest of an incident diagnosis of cancer or death with cancer listed as a cause, death from causes other than cancer, transfer out of the database practice network, or last data collection date for the practice. For the analyses of specific cancers (lung, breast, prostate, colon), follow-up was censored at the first occurrence of any other type of cancer. We examined associations between risk of cancer and use of an angiotensin receptor blocker in two ways. For the primary analysis, we used ever exposed to angiotensin receptor blockers versus never exposed to angiotensin receptor blocker (that is, treatment with an ACE inhibitor only) as the main exposure variable, and, after calculating crude incidence ratios, we included the variable in adjusted Cox regression models for each outcome. The variable ever exposed to angiotensin receptor blocker was treated as time updated so that, for example, people starting treatment with an ACE inhibitor and switching to an angiotensin receptor blocker would contribute initial person time as never exposed to an angiotensin receptor blocker, but person time after the switch as ever exposed to an angiotensin receptor blocker (fig $1 \Downarrow$ ). Once exposed to angiotensin receptor blockers, however, patients remained in the ever exposed group even if they subsequently stopped treatment; we used this strategy because any causal effect of angiotensin receptor blocker use on cancer risk would likely manifest as a diagnosis only some time after harmful exposure. In a secondary analysis, we re-ran our adjusted Cox models using a time updated variable capturing cumulative duration of angiotensin receptor blocker exposure (classified as 12-24, 25-36, 37-48, 48-60, >60 months) in place of the variable ever exposed to an angiotensin receptor blocker. 
Cumulative duration of angiotensin receptor blocker exposure did not increase during treatment interruptions or discontinuations of treatments (fig $1 \Downarrow$ ). In all cases, our Cox models were adjusted for the following potential confounders, evaluated at the index date: age group (18-54, 55-64, 65-74, $\geq 75$, based on approximate quartiles), sex, body mass index (BMI; underweight, normal, overweight/obese), smoking status (non-smoker, current smoker, ex-smoker), alcohol status (non-drinker, ex-drinker, or current drinker-further classified as light, moderate, heavy, unknown), diabetes status (categorised as no evidence of diabetes, diabetes without metformin or insulin use, diabetes with metformin but no insulin use, and diabetes with any insulin use), hypertension (based on a recording of diagnosed hypertension or blood pressure $>140 / 90 \mathrm{~mm} \mathrm{Hg}$ ), heart failure, statin use, index of multiple deprivation score (a measure of socioeconomic status),${ }^{13}$ and calendar year. All of these variables were included because they could plausibly be associated with both treatment and cancer risk. First order interactions between these variables were tested in a preliminary modelling stage, with a cut off of $\mathrm{P}<0.001$ to reflect the number of tests involved (55); this led to the identification of several interactions that were significantly associated with the outcome (between age and sex, BMI and smoking, smoking and index of multiple deprivation score, and heart failure and calendar year). Inclusion of these interactions, however, had little effect on the hazard ratio associated with the exposure of interest - that is, there was no suggestion that omission would lead to confounding - therefore the interactions were not included in subsequent modelling, in the interests of parsimony and ease of interpretation of the final model. For the analyses of risk of breast and prostate cancer, the study population was restricted to women and men, respectively, and sex was omitted from the confounder model. The primary analysis excluded the $10 \%$ of individuals with missing data on smoking, alcohol, or BMI; these patients were included in later sensitivity analyses with missing category and multiple imputation methods to deal with the missing covariates.

To estimate the effect of angiotensin receptor blocker exposure on absolute cancer rates, we included in a Poisson model variables for which our previous Cox model suggested evidence of an association with cancer. The Poisson model was used to predict event rates by exposure to angiotensin receptor blocker in the most recent calendar period (2005 onwards) among those at highest and lowest baseline risk (men aged $\geq 75$ who were current smokers and had a history of heart failure, and women aged 18-54 who had never smoked and had no history of heart failure, respectively). Finally, in an exploratory analyses we examined the role of specific angiotensin receptor blockers (losartan, candesartan, irbesartan, valsartan, telmisartan, other). For this analysis, patients were assumed to be exposed to only a single type of angiotensin receptor blocker during follow-up, taken as the first one prescribed.

\section{Pos hoc analyses, sensitivity analyses, and model checking}

For cancer outcomes that seemed to be associated with use of angiotensin receptor blockers, we assessed (post hoc) associations with use in the initial 12 months of exposure to provide further information on whether the observed associations were likely to represent a causal relation: associations in the first 12 months would argue against this as a causal effect would be unlikely to operate on such a short timescale.

Several planned sensitivity analyses were then carried out. Firstly, we extended our initial 12 month exclusion period after the first prescription for an angiotensin receptor blocker or ACE inhibitor to two and then three years. Secondly, in case of any effect of ACE inhibitor use on cancer risk, we used those prescribed thiazides and related diuretics (as defined by chapter 2.2.1 of the British National Formulary ${ }^{11}$ ) as an alternative comparator group. Thirdly, we repeated the analysis including the $10 \%$ of patients with missing data on smoking, alcohol status, or BMI. We used two methods for handling the missing data: firstly, we introduced a separate missing data category for each of the incomplete variables, and secondly, we used multiple imputation by chained equations, with the imputation model including all covariates from the main outcome model. ${ }^{14}$ Fourthly, we repeated the primary analysis using attained age, rather than time since start of treatment, as the principal time scale, to provide the finest possible control for age. Fifthly, we checked the proportional hazards assumption by testing for a zero slope in the scaled Schoenfeld residuals over time ${ }^{15}$ and, as necessary, introduced interactions with analysis time for any covariates with evidence of non-proportional hazards. Finally, we carried out a post hoc sensitivity analysis, restricting the study population to patients without diabetes because of an imbalance in prevalence of diabetes between treatment groups.

\section{Results Study population, use of antihypertensive
drugs, and baseline characteristics}

Out of 902322 individuals identified with at least one prescription of an angiotensin receptor blocker or ACE inhibitor, 377649 were included in the study with total follow-up of 1.5 million person years (fig $2 \Downarrow$ ). The main exclusions were because of failure to satisfy the new user criteria (that is, less than six months' follow-up in the database before first prescription, $n=279650)$, history of cancer $(n=38834)$, and diagnosis of cancer or end of follow-up during the initial 12 month lag period after start of treatment $(n=206006)$. The median interval from first ever prescription for an ACE inhibitor or angiotensin receptor blocker to the end of follow-up was 4.6 years, with follow-up ending at least five years after the first prescription for 168773 individuals (45\%). A total of 20203 cancers were recorded during follow-up, with the most common specific cancer being prostate $(n=3025)$, followed by breast $(2411)$, lung $(\mathrm{n}=2144)$, and colon $(1516)$.

Of the 377649 individuals in the study, 340589 (90\%) started taking an ACE inhibitor, and 37060 (10\%) started taking an angiotensin receptor blocker. Of the users of ACE inhibitors, however, 71354 (19\% of study population) later switched to an angiotensin receptor blocker; there was little switching in the other direction $(n=3650$, table $1 \Downarrow)$. Of the 1542323 person years, patients spent a total of $346823(22 \%)$ taking an angiotensin receptor blocker and 1070054 (69\%) taking an ACE inhibitor (table $2 \Downarrow$ ). The remaining person time was accounted for by interruptions of treatment (125 446 person years, $8 \%$ ). The most widely used specific angiotensin receptor blockers were losartan, candesartan, irbesartan, and valsartan (accounting for $31 \%, 25 \%, 19 \%$, and 14\% of person time, respectively), while the most common ACE inhibitors were ramipril, lisinopril and perindopril $(43 \%, 29 \%$, and $16 \%$ of person time, respectively).

Those starting and continuing to take ACE inhibitors were more likely to be men (55\% v $\leq 48 \%$ in other groups), while diabetes was more common among those starting treatment with ACE inhibitors, regardless of later switching (baseline prevalence of diabetes $25 \%$, compared with $17 \%$ among those starting treatment with an angiotensin receptor blocker, hence we restricted our post hoc sensitivity analysis to those without 
diabetes). Statin use was also higher among those starting treatment with an ACE inhibitor, but this seemed to be explained by the higher prevalence of diabetes: when we stratified statin use by diabetes status, use was similar across the groups (ranging from $30 \%$ to $40 \%$ among those without diabetes and $57 \%$ to $61 \%$ among those with diabetes). Other baseline characteristics were similar across treatment groups (table $1 \Downarrow$ ). There were some missing data on smoking status (1\%), alcohol status (6\%), and BMI (5\%), but 345 832/377 649 individuals (92\%) had complete data on all variables considered in the analysis.

\section{Effect of ever using an angiotensin receptor blocker}

The overall incidence of cancer was similar among those ever exposed to angiotensin receptor blockers compared with those never exposed. After adjustment for potential confounders, there was no evidence that a small observed increase in risk associated with exposure to an angiotensin receptor blocker represented any more than chance variation (adjusted hazard ratio for ever $v$ never exposed $1.03,95 \%$ confidence interval 0.99 to 1.06 , $\mathrm{P}=0.10$; table $3 \Downarrow$ ). There was some evidence for an association between use of angiotensin receptor blockers and cancers of the breast and prostate (adjusted hazard ratio 1.11, 1.01 to 1.21; and $1.10,1.00$ to 1.20 ; respectively) but not of the colon $(1.02,0.91$ to 1.16$)$. We observed a protective association for lung cancer $(0.84,0.75$ to 0.94$)$.

For those with the highest baseline risk, the estimated absolute increases in incidence of cancer for those ever exposed to angiotensin receptor blockers compared with those never exposed were 0.5 and 1.1 extra cases per 1000 person years for breast and prostate cancer, respectively. For those with the lowest baseline risk, our results suggested an extra 0.2 and 0.1 breast and prostate cancers, respectively, per 1000 person years (table $4 \Downarrow$ ).

\section{Role of cumulative duration of angiotensin receptor blocker use}

Figure 3 shows the effect of cumulative duration of use of angiotensin receptor blockers $\Downarrow$. There was little evidence that the risk for any cancer or specific cancers increased with longer duration of treatment $(\mathrm{P}>0.15$ for trend for any, breast, colon, and prostate cancer). For lung cancer, there was evidence of a decreasing trend $(\mathrm{P}<0.001$ for overall trend and $\mathrm{P}=0.14$ for trend after separate adjustment for ever angiotensin receptor blocker use - that is, ignoring the zero use category).

\section{Effects of treatment with angiotensin receptor blocker in first year of treatment}

For cancer outcomes that seemed to be associated with angiotensin receptor blocker use, we carried out a post hoc analysis to identify any early changes in risk of cancer (in the 12 month period that was excluded from our main analysis) that might suggest non-causal explanations for our findings. For lung cancer, we observed a suggestion of a raised risk of lung cancer in the 12 months after start of treatment with an angiotensin receptor blocker (hazard ratio $1.11,0.99$ to 1.27 ), followed by a protective association with longer duration of treatment. For breast cancer, there was weak evidence of an increased risk associated with angiotensin receptor blockers in the first 12 months of use $(1.12,1.01$ to 1.24$)$, while for prostate cancer the point estimate was in the direction of a raised risk in the first year but the confidence interval suggested that this could have reflected chance variation $(1.07,0.96$ to 1.19$)$.

\section{Role of individual drugs}

To investigate differences between individual angiotensin receptor blockers, we carried out an analysis stratified by the first specific drug prescribed. For $87 \%$ of patients, this represented the only angiotensin receptor blocker to which they were exposed during follow-up. There was a suggestion of a difference between individual drugs in their association with prostate cancer $(\mathrm{P}=0.08)$; the estimated hazard ratios were higher with candesartan and valsartan than with other drugs (table $5 \Downarrow$ ). For breast cancer and other cancer types there was no evidence of a difference between individual drugs ( $\mathrm{P} \geq 0.3$ for interaction in each case).

\section{Sensitivity analyses}

After we extended the one year period of person time excluded after the start of treatment or switching to two and then three years, effect estimates changed little and in all cases confidence intervals included our original effect estimates. The estimated hazard ratios for any cancer were 1.04 (1.00 to 1.08) and 1.03 (0.99 to 1.07) in the two and three year exclusion analyses, respectively. When we used those prescribed thiazides and related diuretics instead of ACE inhibitors as the comparator group, the hazard ratio for any cancer associated with angiotensin receptor blocker use (with adjustment for ACE inhibitor use) was 1.00 (0.95 to 1.05), consistent with no effect on cancer risk. The protective association with lung cancer remained ( $0.77,0.65$ to 0.92$)$, while for breast and prostate cancer the size of the hazard ratios were consistent with the original analysis, though confidence intervals were wider, suggesting reduced power, with risk increases no longer significant (1.11, 0.97 to 1.27 ; and $1.10,0.97$ to 1.24 ; respectively). Our results were robust to the inclusion of the $10 \%$ of individuals with missing data; estimates were similar to our original results, both for any cancer and specific cancers (adjusted hazard ratio associated with ever using an angiotensin receptor blocker for any cancer was 1.03 (0.99 to 1.06) with the missing category analysis and 1.02 (0.99 to 1.06$)$ with the multiple imputation analysis, compared with 1.03 (0.99 to 1.06$)$ in the original analysis). Use of age as the primary timescale rather than time since start of treatment and restriction of the analysis to those without diabetes led to similar effect estimates for the exposure of interest (hazard ratios within 0.01 of our original estimates for any, breast, lung, and prostate cancer and within 0.04 for colon cancer).

There was no evidence of non-proportional hazards for the variable of ever using an angiotensin receptor blocker $(\mathrm{P}=0.72)$, but the hazard ratios associated with age group seemed to change over time $(\mathrm{P}<0.001)$. Inclusion of an interaction between age group and analysis time had little effect on the estimated association between ever using an angiotensin receptor blocker and cancer overall (revised hazard ratio $1.03,1.00$ to 1.07). Estimated hazard ratios for the associations with specific cancers were also in each case within 0.01 of our original estimates.

\section{Discussion}

\section{Main findings}

In a large cohort of new users of ACE inhibitors or angiotensin receptor blockers, we found little evidence of an increase in the overall risk of a diagnosis of cancer associated with ever using an angiotensin receptor blocker, and we were able to rule out any more than a $6 \%$ relative increase in risk (estimated hazard ratio $1.03,95 \%$ confidence interval 0.99 to $1.06, \mathrm{P}=0.10$ ). There was a suggestion that angiotensin receptor blocker use was 
associated with breast cancer in women and prostate cancer in men, but in absolute terms the estimated increases in risk were small: among those with the highest baseline risk, our results suggested one extra case of prostate cancer per 1000 man years exposed and 0.5 extra cases of breast cancer per 1000 woman years exposed. As longer duration of treatment did not seem to be associated with higher risk ( $\mathrm{P}>0.15$ in each case), we cannot exclude non-causal explanations for these observed associations. There was no increase in risk for cancers of the lung or colon; indeed we observed an apparently protective association between use of angiotensin receptor blockers and lung cancer.

\section{Comparison with other studies}

Table 6 presents a summary of key studies to date $\Downarrow$. Clinical concerns surrounding potential cancer risks associated with use of angiotensin receptor blockers arose initially from randomised trial data. The CHARM trial showed weak evidence of an increased risk of deaths from cancer among those randomised to candesartan compared with placebo. ${ }^{2}$ Several meta-analyses have followed up this finding. Coleman et al reported a raised point estimate for the odds ratio for cancer associated with angiotensin receptor blocker treatment, but confidence intervals were wide and included $1 .{ }^{8}$ Sipahi et al found a significantly increased risk of new cancer among those taking angiotensin receptor blockers compared with control treatments, and there was an indication of a raised risk of prostate cancer, though this did not reach formal significance $(\mathrm{P}=0.08)$; in contrast with our results, the authors also observed a significantly increased risk of lung cancer. ${ }^{3}$ Two more recent meta-analyses by the ARB Trialists Collaboration and Bangalore et al failed to confirm these findings, ${ }^{4}{ }^{7}$ reporting no association between angiotensin receptor blocker use and cancer: the ARB Trialists analysis included a wide range of trials and incorporated individual patient data and unpublished tabulated data on cancer outcomes. A few included trials reported a significantly protective effect on lung cancer, and this seemed to cancel out the detrimental effect in the subset of trials included in the earlier Sipahi et al meta-analysis: overall, the authors found no evidence for an altered risk of lung cancer with angiotensin receptor blockers nor any evidence for an excess risk of prostate, breast, or overall cancer. Confidence intervals, however, were somewhat wider than in our study, and it should be noted that positive associations of the size we have estimated for breast and prostate cancer would not be ruled out by the confidence intervals presented in the ARB Trialists analysis, or indeed by the earlier meta-analyses mentioned above.

This issue highlights one of the limitations of trial data in this context: even the most comprehensive meta-analysis included substantially fewer patients than was possible in our study, and follow-up time ranged from 23 months to a maximum of five years, while $45 \%$ of patients in our study had at least five years of follow-up available. In addition, randomised trials in this topic are not designed to detect cancer outcomes, study populations might inadequately represent the wider population of patients treated with angiotensin receptor blockers and similar drug classes, and, even if sufficient follow-up were available, the benefits of randomisation would probably be lost over the long term because of switching, non-adherence, and drop out.

Only a few observational studies to date have investigated the potential cancer risks associated with treatment with angiotensin receptor blockers. A recent study in Denmark reported no increase in overall risk of cancer in the preplanned analysis of angiotensin receptor blocker users compared with ACE inhibitor users, ${ }^{6}$ in agreement with our study. The authors also observed a significantly increased risk of prostate cancer in a post hoc subgroup analysis, a finding that seems to be supported by our study, in which prostate cancer was one of four prespecified site specific outcomes. No increased risk of breast cancer was observed, but confidence intervals were once again consistent with the effect size we have observed. For lung cancer, the estimated relative risk was similar to that in our study, but the confidence interval included the null $(0.92,0.82$ to 1.02$)$.

Finally, a study based on Taiwanese health insurance data reported more contrasting results, with a substantially and significantly reduced risk of cancer observed among those treated with angiotensin receptor blockers, ${ }^{5}$ but this could be explained by broader differences between treated and untreated patients with hypertension, as a large proportion of the control group in this study did not seem to be receiving antihypertensive drugs at all.

\section{Possible mechanisms and explanation of findings}

Experimental evidence could support a role for angiotensin II receptors in the development of cancer. The renin angiotensin system seems to be involved in angiogenesis, but the exact mechanisms involved, and indeed the direction of associations, are not clear. Administration of the angiotensin receptor blocker losartan in animal models has been linked to both increases ${ }^{16}$ and decreases ${ }^{17}$ in angiogenesis. Angiotensin II binds to both type 1 and type 2 receptors (AT1R and AT2R), and one study suggests that stimulation of the latter in particular could be key in mediating in vivo angiogenesis. ${ }^{16}$ It is therefore possible that angiotensin receptor blockers could increase the risk of cancer through removal of the "competition" from AT1R and thus enabling unopposed AT2R stimulation. Other studies, however, implicate AT1R stimulation in angiogenesis through triggering the expression of vascular endothelial and other growth factors ${ }^{18}$ and genes involved in cellular proliferation, ${ }^{19}$ in which case blockade with angiotensin receptor blockers might be expected to be associated with reduced cancer risk; the blocking of AT1R has also been shown to induce apoptosis within tumour cells in vitro. ${ }^{20}$ The contradictory nature of these various observations suggest that complex mechanisms might be at work, and indeed their relevance in humans and in clinical practice is difficult to judge.

The lack of convincing associations between duration and response suggest that we should consider non-causal explanations for our findings. Firstly, the increases in cancer risk that we observed for breast and prostate cancer were not strongly significant and might still reflect chance variation: it is worth noting that tests of five outcomes subject to a simple statistical (Bonferroni) correction for multiple testing would require $\mathrm{P}<0.01$ for a family-wise significance level of $5 \%$. We did not formally apply this correction as, for non-independent outcomes, it would likely be overconservative, ${ }^{21}$ but results with corresponding $\mathrm{P}$ values $>0.01$ must be treated with caution.

\section{Breast cancer}

In a post hoc analysis we observed an increased risk of breast cancer associated even with less than 12 months' exposure to angiotensin receptor blockers, which argues further against a causal relation. A possible mechanism might involve the use of angiotensin receptor blockers in those with cough symptoms. Individuals with cough might be preferentially switched to, or started on angiotensin receptor blockers, as treatment with ACE inhibitors is associated with cough as a side effect. But cough symptoms might themselves be linked to an undiagnosed cancer, or, importantly, to a greater likelihood of referral for chest 
radiography and therefore early detection of preclinical breast cancers. This could explain the immediately increased risk of breast cancer with short duration of treatment, though it would be surprising for such an effect to persist in our primary analysis that excluded the first 12 months of treatment.

\section{Lung cancer}

There was weak evidence for a similar early increase in risk of lung cancer; only after 12 months was the association protective. This would be consistent with a selective switching to angiotensin receptor blockers among those (perhaps with cough symptoms) at risk of an imminent diagnosis of lung cancer, and a consequently depleted pool of individuals at risk of lung cancer among those with longer duration of treatment. It should be noted though that we also observed a protective association between angiotensin receptor blockers and lung cancer in a sensitivity analysis in which we used thiazides and related diuretics as an alternative comparator group. These drugs are not associated with a cough side effect, suggesting that selective switching because of cough associated with ACE inhibitors might not be the full explanation. Another possibility is that increasing cardiovascular risk could lead some patients to simultaneously start a new antihypertensive drug and also reduce their smoking, thus lowering their risk of lung cancer. Whether or not it is causal, it should be noted that the protective association with lung cancer that we observed is consistent with observational data from Denmark ${ }^{6}$ and some individual clinical trials, ${ }^{4}$ and the evidence is strengthened by an apparent association between increasing duration of treatment and greater protection; we therefore think the relation between use of angiotensin receptor blockers and risk of lung cancer is worthy of further study.

\section{Prostate cancer}

There was insufficient evidence to confirm an association between use of angiotensin receptor blockers and prostate cancer during the initial 12 month exclusion period, and confounding because of switching associated with cough is unlikely to be an issue, suggesting that a causal relation could be plausible, but, as with breast cancer, we did not observe a convincing effect of duration of treatment on this outcome.

\section{Public health implications}

Even if the association is causal, the absolute increases in the risk of cancer associated with treatment with an angiotensin receptor blocker that we have observed would need to be weighed up against likely benefits of treatment. In the results of the SCOPE trial among elderly patients with mild to moderate hypertension, treatment with an angiotensin receptor blocker (candesartan) was associated with 2.9 fewer cases of non-fatal stroke per 1000 person years, and non-significant reductions in all stroke and first major cardiovascular event of 3.1 and 3.3 per 1000 person years, respectively. ${ }^{22}$ In the CHARM-Overall study (candesartan versus placebo), about 3800 patients with chronic heart failure in each arm were followed up for a median of 37.7 months. Treatment with an angiotensin receptor blocker was associated with five fewer deaths per 1000 person years. ${ }^{2}$ These figures compare with a maximum estimated increase in cancer risk corresponding to one extra diagnosis of prostate cancer per 1000 man years exposed, and 0.5 extra diagnoses of breast cancer per 1000 woman years exposed, for those with the highest risks of cancer at baseline. Nevertheless, it would be desirable to avoid any increase in the risk of such a serious adverse event. Given that alternative and equally effective antihypertensive drugs exist, ${ }^{23}$ our findings, if confirmed by further evidence suggesting a causal relation, support the consideration of other classes of drugs in the treatment decision process, particularly for patients considered to be at the highest risk of breast or prostate cancer. Further confirmatory studies and a thorough consideration of the risk-benefit balance will be needed before changes to treatment guidelines can be recommended.

\section{Strengths and limitations}

Our study has some limitations. Firstly, patients were not randomised to their treatments. Recent data suggest that observational studies generally give robust estimates of adverse effects, ${ }^{24}$ but care must be taken: in a non-randomised setting, treatment decisions might be linked to the particular circumstances or medical history of the patient. In this case, the decision to use those treated with ACE inhibitors as the main comparison group should have reduced confounding by indication as the two classes of drugs have similar indications. Nevertheless, the reasons for treatment with one class over the other might have been linked to patients' health, particularly given the association of ACE inhibitors with cough. If angiotensin receptor blockers were selectively prescribed to those with underlying health problems associated with cancer, a spurious positive result might have been detected for some cancers. As we also included those switching to an angiotensin receptor blocker during follow-up in our analysis, a non-causal association might have been induced if the reasons for switching were linked to the underlying cancer risk; we dealt with this issue by excluding the 12 months of person time after a switch to an angiotensin receptor blocker, extending this to two and then three years in sensitivity analyses. We also conducted a post hoc analysis of data specifically from the first 12 months of angiotensin receptor blocker use to provide information regarding the likely causality of associations detected.

A further limitation is that we had no direct data on adherence to treatment. We used records of prescriptions to define exposure and some patients, in one or both treatment groups, might not have taken their drugs regularly, resulting in effective misclassification and the potential for bias in either direction. Our study design, however, required that patients had picked up prescriptions for a 12 month period before the start of follow-up, with no more than a 90 day gap between prescriptions. It seems unlikely that a high proportion of non-adherers would have continued to pick up prescriptions in this way for an extended period of time and thus qualified for inclusion in the study. Finally, although our study to our knowledge had longer follow-up than any previous large scale study, given generally long lead times associated with cancer outcomes, we cannot rule out that an important effect might operate at longer timescales.

Despite these limitations, to our knowledge, our study is the largest to date to investigate the concerns surrounding angiotensin receptor blocker use and risk of cancer. We were able to include a large number of patients in a real world clinical setting and with relatively long follow-up: $45 \%$ of our study population had follow-up data for at least five years after the start of treatment. Patients included in General Practice Research Database have been shown to be representative of the wider population ${ }^{25}$ and are not restricted on age or other factors; the use of routinely collected primary healthcare data also allowed us to adjust our analyses for multiple confounders including important lifestyle risk factors such as smoking, BMI, and alcohol use. Finally, we carried out several sensitivity analyses and our findings seemed to be robust to changing elements of 
the study design and analysis and the approach used for dealing with missing data; to using an alternative comparison drug class in case ACE inhibitors themselves had an effect on cancer risk; to restricting the study population to people without diabetes; and to the inclusion of extra terms in the statistical model to allow for non-proportional hazards.

\section{Conclusions}

In a cohort of individuals treated for hypertension, we found no evidence of an overall increased risk of cancer among those exposed to angiotensin receptor blockers and a protective association for lung cancer specifically. There was some evidence that the risk of breast and prostate cancers could be raised, though we cannot rule out non-causal mechanisms. In absolute terms, observed risk increases were relatively small and must be weighed against the likely benefits of treatment. Further research might focus on exploring the apparent protective association with lung cancer, and clarifying whether patients at high risk of breast or prostate cancer would benefit from alternative, equally effective antihypertensive drugs; we recommend that future studies include a careful assessment of the likely causality of any association.

Contributors: KB, ID, SE, TVS, and LS were involved in the design of the study. KB carried out the data management and statistical analysis and wrote the first draft. All authors contributed to further drafts. KB and LS are guarantors.

Funding: This report is independent research arising from a postdoctoral fellowship (for KB) supported by the National Institute for Health Research. The views expressed in this publication are those of the authors and not necessarily those of the NHS, the National Institute for Health Research, or the Department of Health. LS is supported by a Wellcome Trust senior research fellowship in clinical science. ID is supported by an MRC methodology research fellowship. General Practice Research Database (GPRD) is owned by the Secretary of State of the UK Department of Health and operates within the MHRA (Medicines and Healthcare products Regulatory Agency). The views expressed in this paper are those of the authors and do not reflect the official policy or position of the MHRA. The funding sources detailed above had no role in the design, conduct, analysis, or reporting of the study. All authors carried out this research independently of the funding bodies

Competing interests: All authors have completed the ICMJE uniform disclosure form at www.icmje.org/coi_disclosure.pdf (available on request from the corresponding author) and declare: ID has previously received consultancy fees from Takeda (unrelated to the submitted work); the General Practice Research Database (GPRD) has received funding from the MHRA, Wellcome Trust, Medical Research Council, NIHR Health Technology Assessment programme, Innovative Medicine Initiative, UK Department of Health, Technology Strategy Board, Seventh Framework Programme EU, various universities, contract research organisations and pharmaceutical companies; the Department of Pharmacoepidemiology and Pharmacotherapy, Utrecht Institute for Pharmaceutical Sciences, has received unrestricted funding for pharmacoepidemiological research from GlaxoSmithKline, Novo Nordisk, Top Institute Pharma (www.tipharma.nl, includes co-funding from universities, government, and industry), the Dutch Medicines Evaluation Board, and the Dutch Ministry of Health.

Ethical approval: The study was approved by the London School of Hygiene and Tropical Medicine ethics committee (application No 5879).
Data sharing: No additional data available.

1 Deshayes F, Nahmias C. Angiotensin receptors: a new role in cancer? Trends Endocrinol Metab 2005;16:293-9.

2 Pfeffer MA, Swedberg K, Granger CB, Held P, McMurray JJ, Michelson EL, et al. Effects of candesartan on mortality and morbidity in patients with chronic heart failure: the CHARM-Overall programme. Lancet 2003:362:759-66.

3 Sipahi I, Debanne SM, Rowland DY, Simon DI, Fang JC. Angiotensin-receptor blockade and risk of cancer: meta-analysis of randomised controlled trials. Lancet Oncol 2010;11:627-36.

4 ARB Trialists Collaboration. Effects of telmisartan, irbesartan, valsartan, candesartan, and losartan on cancers in 15 trials enrolling 138,769 individuals. $J$ Hypertens 2011;29:623-35

5 Huang CC, Chan WL, Chen YC, Chen TJ, Lin SJ, Chen JW, et al. Angiotensin II receptor blockers and risk of cancer in patients with systemic hypertension. Am J Cardiol 2011;107:1028-33.

6 Pasternak B, Svanstrom H, Callreus T, Melbye M, Hviid A. Use of angiotensin receptor blockers and the risk of cancer. Circulation 2011;123:1729-36.

7 Bangalore S, Kumar S, Kjeldsen SE, Makani H, Grossman E, Wetterslev J, et al. Antihypertensive drugs and risk of cancer: network meta-analyses and trial sequential analyses of 324,168 participants from randomised trials. Lancet Oncol 2011;12:65-82.

8 Coleman $\mathrm{Cl}$, Baker WL, Kluger J, White CM. Antihypertensive medication and their impact on cancer incidence: a mixed treatment comparison meta-analysis of randomized controlled trials. J Hypertens 2008;26:622-9.

9 Herrett E, Thomas SL, Schoonen WM, Smeeth L, Hall AJ. Validation and validity of diagnoses in the General Practice Research Database: a systematic review. Br J Clin Pharmacol 2010;69:4-14.

10 Ray WA. Evaluating medication effects outside of clinical trials: new-user designs. Am J Epidemiol 2003;158:915-20.

11 British Medical Association, Royal Pharmaceutical Society of Great Britain. British national formulary. BMA, RPS, 2011: No 61

12 NHS Connecting for Health. Read codes. 2011. www.connectingforhealth.nhs.uk/ systemsandservices/data/uktc/readcodes.

13 Department for Communities and Local Government. Index of multiple deprivation. 2011. http://data.gov.uk/dataset/index-of-multiple-deprivation.

14 White IR, Royston P, Wood AM. Multiple imputation using chained equations: Issues and guidance for practice. Stat Med 2011;30:377-99.

15 Grambsch PM, Therneau TM. Proportional hazards tests and diagnostics based on weighted residuals. Biometrika 1994;81:515-26.

16 Walther T, Menrad A, Orzechowski HD, Siemeister G, Paul M, Schirner M. Differential regulation of in vivo angiogenesis by angiotensin II receptors. FASEB J 2003;17:2061-7.

17 Munzenmaier DH, Greene AS. Opposing actions of angiotensin II on microvascular growth and arterial blood pressure. Hypertension 1996:27:760-5.

18 Greene AS, Amaral SL. Microvascular angiogenesis and the renin-angiotensin system. Curr Hypertens Rep 2002;4:56-62.

19 Sadoshima J, Izumo S. Signal transduction pathways of angiotensin II-induced c-fos gene expression in cardiac myocytes in vitro. Roles of phospholipid-derived second messengers. Circ Res 1993;73:424-38.

20 Gong Q, Davis M, Chipitsyna G, Yeo CJ, Arafat HA. Blocking angiotensin II type 1 recepto triggers apoptotic cell death in human pancreatic cancer cells. Pancreas 2010;39:581-94

21 Bland JM, Altman DG. Multiple significance tests: the Bonferroni method. BMJ 1995;310:170.

22 Lithell H, Hansson L, Skoog I, Elmfeldt D, Hofman A, Olofsson B, et al. The study on cognition and prognosis in the elderly (SCOPE): principal results of a randomized double-blind intervention trial. J Hypertens 2003;21:875-86.

23 Matchar DB, McCrory DC, Orlando LA, Patel MR, Patel UD, Patwardhan MB, et al. Systematic review: comparative effectiveness of angiotensin-converting enzyme inhibitors and angiotensin II receptor blockers for treating essential hypertension. Ann Intern Med 2008;148:16-29.

24 Golder S, Loke YK, Bland M. Meta-analyses of adverse effects data derived from randomised controlled trials as compared to observational studies: methodological overview. PLoS Med 2011:8:e1001026.

25 Parkinson JP, Davis S, Van Staa T. The General Practice Research Database: now and the future. In: Mann R, Andrews EB, eds. Pharmacovigilance. John Wiley, 2007:341-8.

26 Koomen ER, Herings RM, Guchelaar HJ, Nijsten T. Melanoma incidence and exposure to angiotensin-converting enzyme inhibitors and angiotensin receptor blockers. Cancer Epidemiol 2009;33:391-5.

27 Fryzek JP, Poulsen AH, Lipworth L, Pedersen L, Norgaard M, McLaughlin JK, et al. A cohort study of antihypertensive medication use and breast cancer among Danish women. Breast Cancer Res Treat 2006;97:231-6.

28 Fryzek JP, Poulsen AH, Johnsen SP, McLaughlin JK, Sorensen HT, Friis S. A cohort study of antihypertensive treatments and risk of renal cell cancer. Br J Cancer 2005;92:1302-6.

Accepted: 14 March 2012

\section{Cite this as: BMJ 2012;344:e2697}

This is an open-access article distributed under the terms of the Creative Commons Attribution Non-commercial License, which permits use, distribution, and reproduction in any medium, provided the original work is properly cited, the use is non commercial and is otherwise in compliance with the license. See: http://creativecommons.org/licenses/by$\mathrm{nc} / 2.0 /$ and http://creativecommons.org/licenses/by-nc/2.0/legalcode. 


\section{What is already known on this topic}

Experimental studies suggest that angiotensin II receptors play a role in regulating angiogenesis, cell proliferation, and tumour progression, suggesting a theoretical pathway through which drugs affecting the rennin-angiotensin system could modify cancer risk

Data from a clinical trial and subsequent meta-analysis suggested an increased risk of cancer outcomes among people randomised to angiotensin receptor blockers, but a more recent meta-analysis found no such effect

\section{What this study adds}

Exposure to angiotensin receptor blockers was not associated with an increased risk of cancer overall in a UK primary care setting, and there was a protective association with lung cancer

There was an increased risk of breast and prostate cancer among those exposed to angiotensin receptor blockers: for those with the highest baseline risk, exposure was associated with one extra case per 2000 woman years and 1000 man years, respectively

Longer duration of treatment did not seem to be associated with increasing risk for any cancer type, suggesting that observed risk increases might have non-causal explanations

\section{Tables}

Table 1| Baseline and demographic characteristics by treatment use during follow-up in people prescribed angiotensin receptor blockers (ARB) or angiotensin converting enzyme (ACE) inhibitors for hypertension. Figures are numbers (percentage) unless otherwise specified

\begin{tabular}{|c|c|c|c|c|c|}
\hline & ARB only & $\begin{array}{l}\text { Switch from ARB to ACE } \\
\text { inhibitor }\end{array}$ & ACE inhibitor only & Switch from ACE inhibitor to ARB & Total \\
\hline No of patients & $33410(9)$ & $3650(1)$ & $269235(71)$ & $71354(19)$ & $377649(100)$ \\
\hline \multicolumn{6}{|l|}{ Sex: } \\
\hline Men & $15155(45)$ & $1748(48)$ & $148633(55)$ & $31278(44)$ & $196814(52)$ \\
\hline Women & $18255(55)$ & $1902(52)$ & $120602(45)$ & $40076(56)$ & $180835(48)$ \\
\hline \multicolumn{6}{|l|}{ Age (years): } \\
\hline $18-54$ & $8627(26)$ & $925(25)$ & $69374(26)$ & $16038(22)$ & $94964(25)$ \\
\hline $55-64$ & $8864(27)$ & $999(27)$ & $69579(26)$ & $19497(27)$ & $98939(26)$ \\
\hline $65-74$ & $8676(26)$ & $979(27)$ & $67894(25)$ & $21067(30)$ & $98616(26)$ \\
\hline$\geq 75$ & $7243(22)$ & $747(20)$ & $62388(23)$ & $14752(21)$ & $85130(23)$ \\
\hline Median (range) & $64(18-103)$ & $64(21-95)$ & $64(18-103)$ & $65(18-99)$ & $64(18-103)$ \\
\hline \multicolumn{6}{|l|}{ Smoking status: } \\
\hline Non-smoker & $18824(56)$ & $1984(54)$ & $132843(49)$ & $39717(56)$ & $193368(51)$ \\
\hline Current smoker & $5326(16)$ & $656(18)$ & $50774(19)$ & $9834(14)$ & $66590(18)$ \\
\hline Ex-smoker & $9122(27)$ & $1008(28)$ & 83251 (31) & $21616(30)$ & $114997(30)$ \\
\hline Missing & $138(0)$ & $2(0)$ & $2367(1)$ & $187(0)$ & $2694(1)$ \\
\hline \multicolumn{6}{|l|}{ Alcohol status: } \\
\hline Non-drinker & $6469(19)$ & $754(21)$ & $47881(18)$ & $12876(18)$ & $67980(18)$ \\
\hline Current (low) & $7417(22)$ & $783(21)$ & $60364(22)$ & $16902(24)$ & $85466(23)$ \\
\hline Current (moderate) & $605(2)$ & $97(3)$ & $5153(2)$ & $1260(2)$ & $7115(2)$ \\
\hline Current (high) & $404(1)$ & $43(1)$ & $4093(2)$ & $721(1)$ & $5261(1)$ \\
\hline Current (unknown) & $15618(47)$ & $1731(47)$ & $128360(48)$ & 34876 (49) & $180585(48)$ \\
\hline Ex-drinker & $735(2)$ & $78(2)$ & $6815(3)$ & $1529(2)$ & $9157(2)$ \\
\hline Missing & $2162(6)$ & $164(4)$ & $16569(6)$ & $3190(4)$ & $22085(6)$ \\
\hline \multicolumn{6}{|l|}{ BMI category: } \\
\hline Underweight & $849(3)$ & $74(2)$ & $7150(3)$ & $1316(2)$ & $9389(2)$ \\
\hline Normal & 7081 (21) & $768(21)$ & $57721(21)$ & $14402(20)$ & $79972(21)$ \\
\hline Overweight/obese & $23774(71)$ & $2665(73)$ & $189574(70)$ & $53340(75)$ & $269353(71)$ \\
\hline Missing & $1706(5)$ & $143(4)$ & $14790(5)$ & $2296(3)$ & $18935(5)$ \\
\hline \multicolumn{6}{|l|}{ Diabetes: } \\
\hline Yes & $5646(17)$ & $664(18)$ & $68196(25)$ & $17386(24)$ & $91892(24)$ \\
\hline No & $27764(83)$ & $2986(82)$ & 201039 (75) & $53968(76)$ & 285757 (76) \\
\hline
\end{tabular}

Hypertension: 
Table 1 (continued)

\begin{tabular}{lccccc} 
& ARB only & $\begin{array}{c}\text { Switch from ARB to ACE } \\
\text { inhibitor }\end{array}$ & ACE inhibitor only Switch from ACE inhibitor to ARB & Total \\
Yes & $32791(98)$ & $3588(98)$ & $255103(95)$ & $69197(97)$ & $360679(96)$ \\
\hline No & $619(2)$ & $62(2)$ & $14132(5)$ & $2157(3)$ & $16970(4)$ \\
\hline Heart failure: & & & & \\
\hline Yes & $989(3)$ & $108(3)$ & $21831(8)$ & $4553(6)$ & $27481(7)$ \\
\hline No & $32421(97)$ & $3542(97)$ & $247404(92)$ & $66801(94)$ & $350168(93)$ \\
\hline Statin use: & & & & \\
\hline Yes & $11892(36)$ & $1216(33)$ & $122042(45)$ & $29773(42)$ & $164923(44)$ \\
\hline No & $21518(64)$ & $2434(67)$ & $147193(55)$ & $41581(58)$ & $212726(56)$ \\
\hline Median (IQR) deprivation score & $15.6(10.8-22.6)$ & $15.9(11.4-24.5)$ & $16.1(11.1-23.9)$ & $15.1(10.6-22.8)$ & $15.9(10.9-23.7)$ \\
\hline Median (IQR) calendar year & $2005(2003-7)$ & $2004(2002-6)$ & $2006(2003-8)$ & $2005(2003-8)$ & $2005(2003-8)$ \\
\hline
\end{tabular}

IQR=interquartile range.

*Index of multiple deprivation. 
Table 2| Use of specific drugs during follow-up time* during which people were taking angiotensin receptor blocker or angiotensin converting enzyme (ACE) inhibitor

Person years (\% person timet)

Angiotensin receptor blocker

\begin{tabular}{lc}
\hline Losartan & $106115(31)$ \\
\hline Candesartan & $86904(25)$ \\
\hline Irbesartan & $65233(19)$ \\
\hline Valsartan & $49748(14)$ \\
\hline Telmisartan & $17999(5)$ \\
\hline Olmesartan & $13731(4)$ \\
\hline Eprosartan & $7590(2)$ \\
\hline Total & $346823(100)$ \\
\hline ACE inhibitor & $460179(43)$ \\
\hline Ramipril & $310415(29)$ \\
\hline Lisinopril & $175388(16)$ \\
\hline Perindopril & $90877(9)$ \\
\hline Enalapril & $11641(1)$ \\
\hline Captopril & $7831(1)$ \\
\hline Trandolapril & $7056(1)$ \\
\hline Fosinopril & $6183(1)$ \\
\hline Quinapril & $777(<1)$ \\
\hline Cilazapril & $740(<1)$ \\
\hline Imidapril & $19(<1)$ \\
\hline Toexipril & $070054(100)$ \\
\hline
\end{tabular}

*Further 125446 person years accounted for by breaks in treatment. †Person time on combinations of drugs contributes to $>1$ row. 
Table 3| Rate of any and specific cancers by treatment and crude and adjusted hazard ratios in people with hypertension taking angiotensin receptor blocker (ARB) or angiotensin converting enzyme (ACE) inhibitor

\begin{tabular}{|c|c|c|c|c|c|c|}
\hline & \multirow[b]{2}{*}{ Total cancers } & \multirow[b]{2}{*}{ Total person time } & \multirow{2}{*}{$\begin{array}{c}\text { Rate per } 1000 \text { person } \\
\text { years }(95 \% \mathrm{Cl})\end{array}$} & \multicolumn{2}{|c|}{$\mathrm{HR}(95 \% \mathrm{Cl})$} & \multirow[b]{2}{*}{$P$ valuet } \\
\hline & & & & Crude & Adjusted* & \\
\hline \multicolumn{7}{|l|}{ Any cancer } \\
\hline Ever used ARB & 5077 & 385101 & 13.2 (12.8 to 13.6$)$ & 0.99 (0.96 to 1.02$)$ & 1.03 (0.99 to 1.06$)$ & \multirow[t]{2}{*}{0.10} \\
\hline ACE inhibitor use only & 15126 & 1157222 & $13.1(12.9$ to 13.3$)$ & $1.00 \ddagger$ & $1.00 \ddagger$ & \\
\hline \multicolumn{7}{|l|}{ Lung cancer } \\
\hline Ever used ARB & 422 & 385101 & $1.1(1.0$ to 1.2$)$ & 0.72 (0.65 to 0.80$)$ & $0.84(0.75$ to 0.94$)$ & \multirow[t]{2}{*}{0.003} \\
\hline ACE inhibitor use only & 1722 & 1157222 & 1.5 (1.4 to 1.6$)$ & $1.00 \ddagger$ & $1.00 \ddagger$ & \\
\hline \multicolumn{7}{|l|}{ Breast cancer } \\
\hline Ever used ARB & 780 & 221072 & 3.5 (3.3 to 3.8$)$ & $1.11(1.02$ to 1.21$)$ & $1.11(1.01$ to 1.21$)$ & \multirow[t]{2}{*}{0.02} \\
\hline ACE inhibitor use only & 1631 & 523186 & 3.1 (3.0 to 3.3 ) & $1.00 \ddagger$ & $1.00 \ddagger$ & \\
\hline \multicolumn{7}{|l|}{ Prostate cancer } \\
\hline Ever used ARB & 700 & 164029 & $4.3(4.0$ to 4.6$)$ & $1.14(1.05$ to 1.24$)$ & $1.10(1.00$ to 1.20$)$ & \multirow[t]{2}{*}{0.04} \\
\hline ACE inhibitor use only & 2325 & 634035 & 3.7 (3.5 to 3.8$)$ & $1.00 \ddagger$ & $1.00 \ddagger$ & \\
\hline \multicolumn{7}{|l|}{ Colon cancer } \\
\hline Ever used ARB & 384 & 385101 & $1.0(0.9$ to 1.1$)$ & 0.99 (0.88 to 1.11$)$ & $1.02(0.91$ to 1.16$)$ & \multirow[t]{2}{*}{0.70} \\
\hline ACE inhibitor use only & 1132 & 1157222 & $1.0(0.9$ to 1.0$)$ & $1.00 \ddagger$ & $1.00 \ddagger$ & \\
\hline \multicolumn{7}{|c|}{ 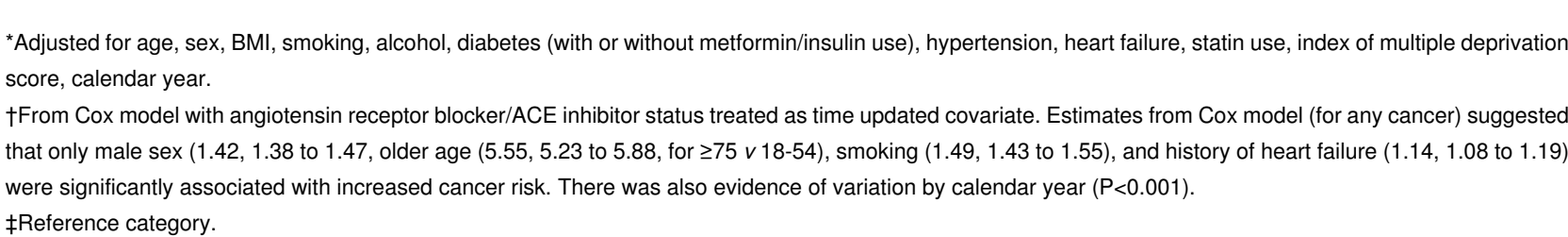 } \\
\hline
\end{tabular}


Table 4 | Estimated effect of ever versus never using angiotensin receptor blocker (ARB) on absolute estimates of cancer incidence. ${ }^{\star}$ Figures are estimated incidence rate (per 1000 person years)

\begin{tabular}{|c|c|c|c|c|c|c|}
\hline & \multicolumn{3}{|c|}{ Low risk group $†$} & \multicolumn{3}{|c|}{ High risk group $\ddagger$} \\
\hline & $\begin{array}{c}\text { Used ACE } \\
\text { inhibitors only }\end{array}$ & Ever used ARB & $\begin{array}{c}\text { Difference } \\
\text { (ARB-ACE } \\
\text { inhibitor) }\end{array}$ & $\begin{array}{c}\text { Used ACE } \\
\text { inhibitors only }\end{array}$ & Ever used ARB & $\begin{array}{c}\text { Difference } \\
\text { (ARB-ACE } \\
\text { inhibitor) }\end{array}$ \\
\hline Any cancer & 3.1 & 3.2 & 0.1 & 40.9 & 42.6 & 1.6 \\
\hline Lung cancer & 0.1 & 0.1 & 0.0 & 14.7 & 12.3 & -2.5 \\
\hline Breast cancer & 2 & 2.2 & 0.2 & 4.3 & 4.8 & 0.5 \\
\hline Prostate cancer & 0.7 & 0.8 & 0.1 & 7.2 & 8.3 & 1.1 \\
\hline Colon cancer & 0.2 & 0.2 & 0.0 & 2.6 & 2.8 & 0.1 \\
\hline
\end{tabular}

ACE inhibitor=angiotensin converting enzyme inhibitor.

*Incidence rates predicted for calendar period 2005-11 from Poisson model incorporating exposure of interest, along with strongest predictors of cancer risk from main Cox model (age, sex, smoking status, heart failure, calendar period).

†Age 18-54, never smoker, no previous heart failure, and (for non-sex specific cancers) female.

$\ddagger$ Age $\geq 75$, current smoker, previous heart failure, and (for non-sex specific cancers) male. 
Table 5| Effect of ever versus never* using angiotensin receptor blocker (ARB), stratified by first specific drug used, on risk of specific cancers

\begin{tabular}{|c|c|}
\hline Specific drug & Hazard ratio $(95 \% \mathrm{Cl})$ \\
\hline \multicolumn{2}{|l|}{ Any cancer } \\
\hline Losartan & 1.04 (0.98 to 1.09 ) \\
\hline Candesartan & 1.04 (0.98 to 1.11 ) \\
\hline Irbesartan & $1.02(0.95$ to 1.09$)$ \\
\hline Valsartan & 1.04 (0.96 to 1.12$)$ \\
\hline Telmisartan & 0.99 (0.87 to 1.14$)$ \\
\hline Other & $0.97(0.85$ to 1.10$)$ \\
\hline \multicolumn{2}{|l|}{ Lung cancer } \\
\hline Losartan & $0.84(0.70$ to 1.00$)$ \\
\hline Candesartan & $0.99(0.81$ to 1.21$)$ \\
\hline Irbesartan & 0.71 (0.55 to 0.93$)$ \\
\hline Valsartan & $0.90(0.70$ to 1.16$)$ \\
\hline Telmisartan & $0.78(0.48$ to 1.25$)$ \\
\hline Other & 0.60 (0.36 to 1.02$)$ \\
\hline \multicolumn{2}{|l|}{ Breast cancer } \\
\hline Losartan & 1.04 (0.91 to 1.19$)$ \\
\hline Candesartan & 1.07 (0.90 to 1.26$)$ \\
\hline Irbesartan & 1.11 (0.92 to 1.33$)$ \\
\hline Valsartan & 1.19 (0.99 to 1.44$)$ \\
\hline Telmisartan & $1.36(1.00$ to 1.86$)$ \\
\hline Other & 1.34 (0.99 to 1.81$)$ \\
\hline \multicolumn{2}{|c|}{ Prostate cancer } \\
\hline Losartan & 0.98 (0.85 to 1.13$)$ \\
\hline Candesartan & $1.32(1.13$ to 1.54$)$ \\
\hline Irbesartan & 1.04 (0.86 to 1.27$)$ \\
\hline Valsartan & 1.17 (0.97 to 1.43$)$ \\
\hline Telmisartan & $1.03(0.72$ to 1.47$)$ \\
\hline Other & 0.96 (0.67 to 1.37$)$ \\
\hline \multicolumn{2}{|l|}{ Colon cancer } \\
\hline Losartan & 1.14 (0.96 to 1.37$)$ \\
\hline Candesartan & 0.89 (0.70 to 1.14$)$ \\
\hline Irbesartan & $1.08(0.85$ to 1.39$)$ \\
\hline Valsartan & 0.93 (0.70 to 1.24$)$ \\
\hline Telmisartan & 0.90 (0.54 to 1.51$)$ \\
\hline Other & 0.95 (0.59 to 1.54$)$ \\
\hline
\end{tabular}

${ }^{*}$ Comparison group was patients who had taken only ACE inhibitor. 


\begin{tabular}{|c|c|c|c|c|c|}
\hline & \multirow{2}{*}{$\begin{array}{l}\text { Exposed to } \\
\text { ARB/total }\end{array}$} & \multirow[b]{2}{*}{ Description } & \multirow{2}{*}{$\begin{array}{l}\text { Main comparison } \\
\text { group }\end{array}$} & \multicolumn{2}{|c|}{ Cancer result } \\
\hline & & & & Any & Site specific \\
\hline \multicolumn{6}{|l|}{ Trial data } \\
\hline Pfeffer, $2003^{2}$ & $3803 / 7601$ & CHARM efficacy trial & Placebo & $\begin{array}{l}\text { Fatal: } 2.3 \% \vee 1.6 \% \text {, } \\
\mathrm{P}=0.038 ; \text { non-fatal: } \\
5.1 \% \vee 4.6 \%, \mathrm{P}=0.49\end{array}$ & - \\
\hline \multicolumn{6}{|c|}{ Meta-analyses of randomised trials } \\
\hline $\begin{array}{l}\text { ARB trialists } \\
\text { collaboration, } \\
2011^{4}\end{array}$ & $73808 / 138760$ & $\begin{array}{l}\text { Trials of antihypertensive drugs; individual } \\
\text { patient data/tabulated data on cancer } \\
\text { outcomes available }\end{array}$ & $\begin{array}{l}\text { Placebo ( } 11 \text { trials); ACE } \\
\text { inhibitor ( } 2 \text { trials); others } \\
\text { (2 trials) }\end{array}$ & $1.00(0.95 \text { to } 1.04)^{*}$ & $\begin{array}{l}\text { Lung: } 1.01(0.90 \text { to } 1.14) \\
\text { prostate: } 1.04(0.93 \text { to } 1.16) ; \\
\text { breast: } 1.08(0.92 \text { to } 1.27)^{\star}\end{array}$ \\
\hline Bangalore, $2011^{7}$ & $41454 / 324168$ & $\begin{array}{l}\text { Trials of antihypertensive drugs with } \\
\text { reported data on cancer outcomes, or } \\
\text { where such information could be obtained } \\
\text { from investigators }\end{array}$ & Mixed control groups & $\begin{array}{c}1.01(0.93 \text { to } 1.09)^{*} \\
\quad v \text { placebo }\end{array}$ & - \\
\hline Sipahi, $2010^{3}$ & 35 015/61 590 & $\begin{array}{l}\text { Trials of ARB with reported data on cancer } \\
\text { outcomes }\end{array}$ & $\begin{array}{l}\text { Placebo ( } 3 \text { trials); ACE } \\
\text { inhibitor ( } 1 \text { trial); other } \\
\text { (1 trial) }\end{array}$ & $1.08(1.01$ to 1.15$) \dagger$ & $\begin{array}{l}\text { Lung: } 1.25,1.05 \text { to } 1.49) \text {; } \\
\text { prostate: } 1.15 \text { ( } 0.99 \text { to } 1.34) \\
\text { breast: } 0.99(0.74 \text { to } 1.32) \dagger\end{array}$ \\
\hline Coleman, $2008^{8}$ & $9550 / 126137$ & $\begin{array}{l}\text { Trials of antihypertensive drugs reporting } \\
\text { data on overall cancer incidence }\end{array}$ & Mixed control groups & $\begin{array}{c}1.12(0.87 \text { to } 1.47)^{\star} \\
\quad v \text { placebo }\end{array}$ & - \\
\hline \multicolumn{6}{|c|}{ Observational studies } \\
\hline Pasternak, $2011^{6}$ & $107466 / 317158$ & $\begin{array}{l}\text { Database study with Danish registry data, } \\
\text { including those with record of ARB or ACE } \\
\text { inhibitor use }\end{array}$ & ACE inhibitor users & $0.99(0.95$ to 1.03$) \dagger$ & $\begin{array}{l}\text { Lung: } 0.92 \text { ( } 0.82 \text { to } 1.02) \text {; male } \\
\text { genital organs: } 1.15(1.02 \text { to } \\
\text { 1.28); breast: } 1.01 \text { ( } 0.90 \text { to } 1.13) \text {; } \\
\text { digestive organs: } 0.96 \text { ( } 0.88 \text { to } \\
1.04) \dagger\end{array}$ \\
\hline Huang, $2011^{5}$ & 40 124/109 002 & $\begin{array}{l}\text { Study using Taiwanese health insurance } \\
\text { data, including patient with diagnosis of } \\
\text { hypertension (but not necessarily treated) }\end{array}$ & Exposed $v$ not exposed & $0.66(0.63$ to 0.68$) \neq$ & $\begin{array}{l}\text { Lung: } 0.57 \text { ( } 0.49 \text { to } 0.66) \text {; } \\
\text { genitourinary system: } 0.67 \text { ( } 0.59 \\
\text { to } 0.76) \text {; breast: } 0.66 \text { ( } 0.52 \text { to } \\
0.82) ; \text { digestive system: } 0.63 \\
(0.58 \text { to } 0.69) \ddagger\end{array}$ \\
\hline Koomen, $2009^{27}$ & $\begin{array}{l}\text { 30/1318 cases; } \\
148 / 6786 \text { controls }\end{array}$ & $\begin{array}{l}\text { Case control study with melanoma cases } \\
\text { and matched controls, with Dutch drug and } \\
\text { pathology databases }\end{array}$ & Exposed $v$ not exposed & - & Melanoma: $1.1(0.7 \text { to } 1.5)^{\star}$ \\
\hline Fryzek, $2006^{28}$ & $3053 / 49950$ & $\begin{array}{l}\text { Database study with Danish registry data, } \\
\text { including those with record of } \\
\text { antihypertensive drug use }\end{array}$ & Exposed $v$ not exposed & - & Breast: $1.01(0.67$ to 1.51$) \dagger$ \\
\hline Fryzek, $2005^{29}$ & $13755 / 113298$ & $\begin{array}{l}\text { Database study with Danish registry data, } \\
\text { including those with record of } \\
\text { antihypertensive drug use }\end{array}$ & Exposed $v$ not exposed & - & Renal: 1.1 (0.6 to 2.2$) \dagger$ \\
\hline $\begin{array}{l}\text { *Odds ratio. } \\
\text { †Rate ratio. } \\
\text { †Hazard ratio. }\end{array}$ & & & & & \\
\hline
\end{tabular}




\section{Figures}

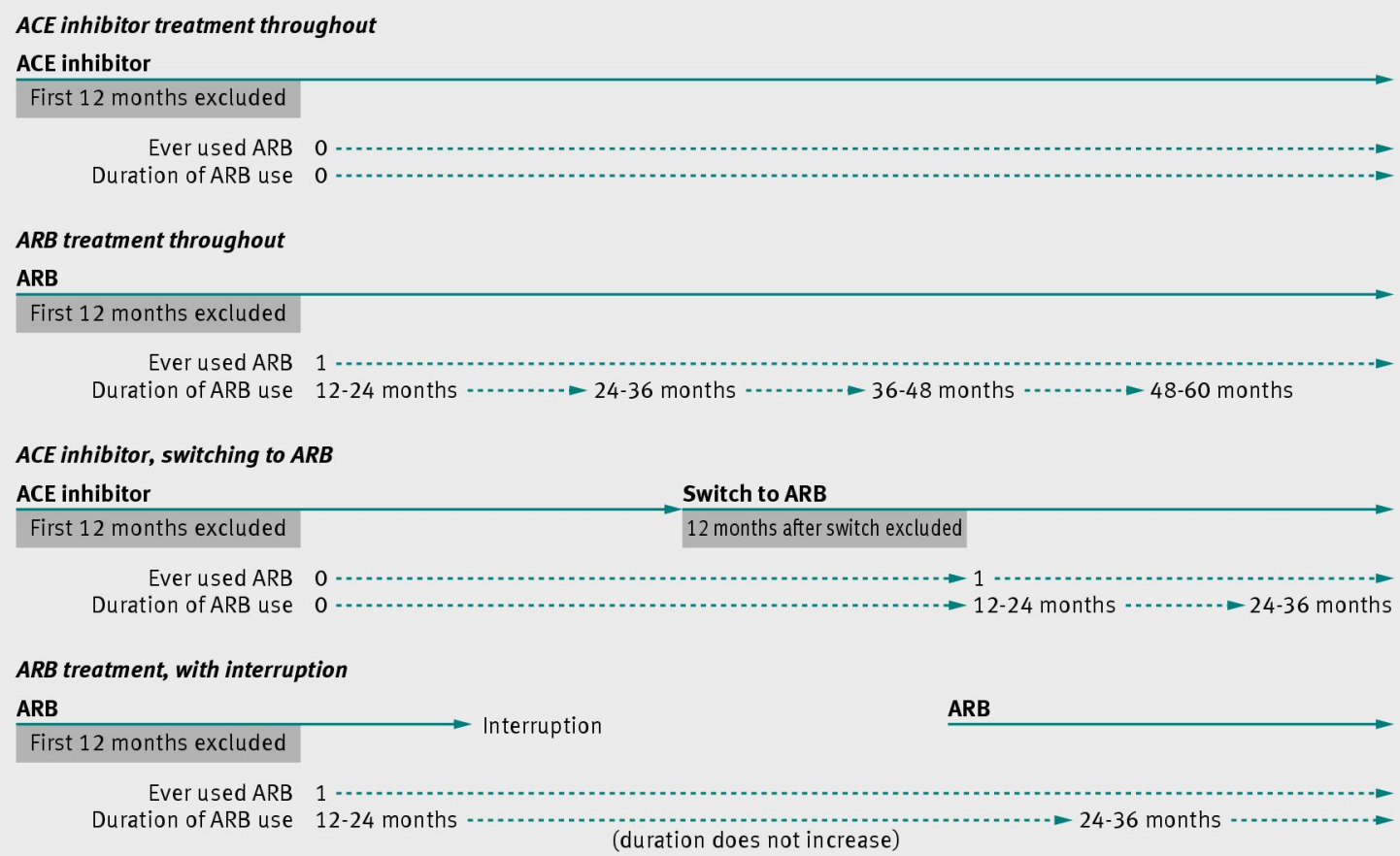

Fig 1 Assignation of time varying variable for ever exposed to angiotensin receptor blocker (ARB) and duration of angiotensin receptor blocker use during follow-up under four example scenarios

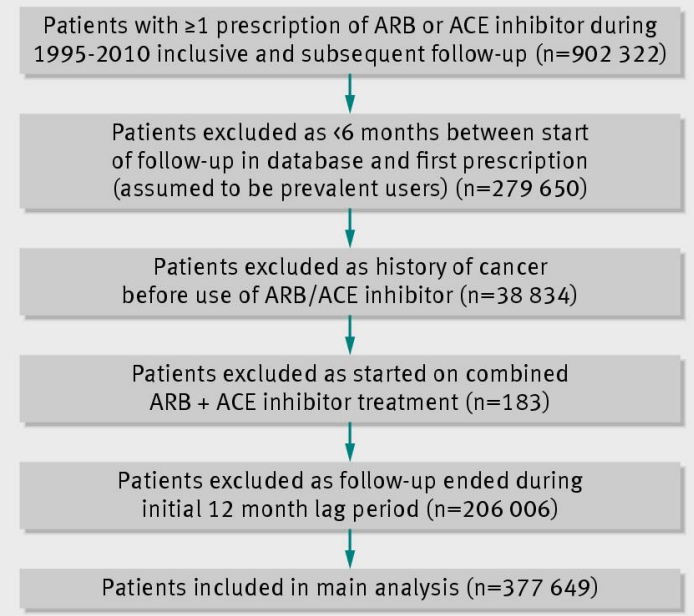

Fig 2 Inclusion and exclusion of study participants. ARB=angiotensin receptor blocker 


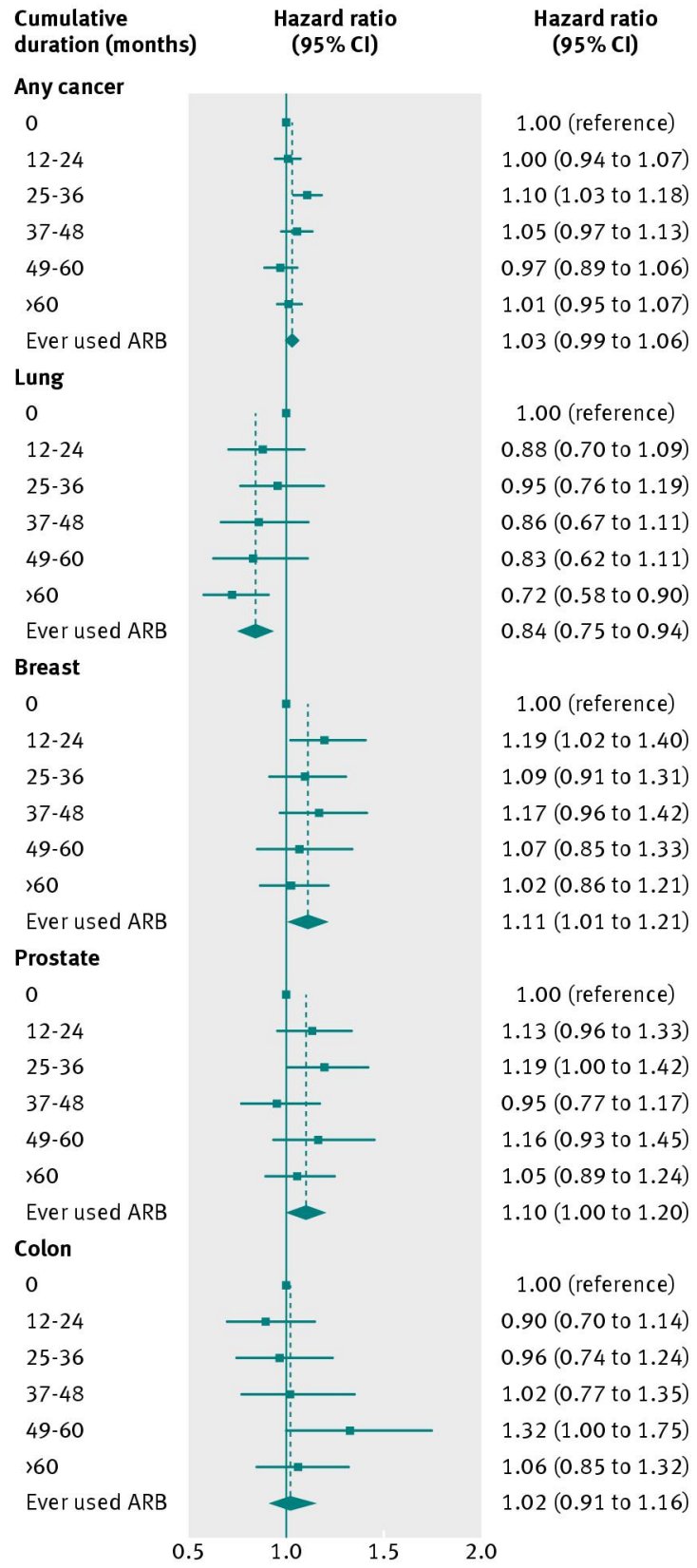

Fig 3 Effect of cumulative duration (from end of initial one year qualifying treatment period) of angiotensin receptor blocker (ARB) use on risk of all cancer and specific cancers. Hazard ratios are from Cox models with cumulative duration of use treated as time updated covariate, adjusted for age, sex (except models for breast/prostate cancers), BMI, smoking, alcohol, diabetes, metformin use, index of multiple deprivation score, and calendar year. Effect estimate for "ever used" is from primary analysis model ignoring number of prescriptions and is shown for comparison 